\title{
Cloning and characterization of a putative gene encoding serine protease inhibitor (251Hbpi) with antifungal activity against Trichophyton rubrum from Hevea brasiliensis leaves
}

\author{
Dutsadee Chinnapun $^{1, *}$, Sarawoot Palipoch ${ }^{1}$, Hatairat Hongphruk ${ }^{2}$ \\ ${ }^{1}$ School of Medicine, Walailak University, Nakhon Si Thammarat 80161, Thailand \\ ${ }^{2}$ Center for Scientific and Technological Equipments, Walailak University, Nakhon Si Thammarat 80161, \\ Thailand
}

*Corresponding author: dutsadee.ch@wu.ac.th

\begin{abstract}
A novel serine protease inhibitor gene was isolated from Hevea brasiliensis leaves, a RRIT251 cultivar and designated RRIT251 $H$. brasiliensis protease inhibitor $(251 \mathrm{Hbpi})$. Reverse transcription polymerase chain reaction (RT-PCR) and rapid amplification of cDNA ends (RACE) were used to isolate 251 Hbpi. A full-length cDNA of $251 \mathrm{Hbpi}$ encoded a 70 amino acid protein. $251 \mathrm{HbPI}$ is a member of the potato inhibitor I (PI-I) family of serine protease inhibitors. The amino acid residues at the active site of $251 \mathrm{HbPI}$ were predicted as $\mathrm{Met}^{46}-\mathrm{Glu}^{47}$. Multiple alignments of the homologous PI-I family revealed one motif WPELVG of $251 \mathrm{HbPI}$ conserved across the family. 251 Hbpi was cloned into expression vector pFLAG-ATS and expressed in Escherichia coli strain BL21. Molecular weight of the recombinant $251 \mathrm{HbPI}(\mathrm{r} 251 \mathrm{HbPI})$ was approximately $11 \mathrm{kDa}$. Protease inhibition analysis revealed that r251HbPI inhibited the activity of chymotrypsin and subtilisin A but did not trypsin protease. Moreover, purified r251HbPI protein inhibited Trichophyton rubrum with a minimum inhibitory concentration of $0.7 \mathrm{mg} / \mathrm{ml}$ and a minimum fungicidal concentration of $1.4 \mathrm{mg} / \mathrm{ml}$. The specific T. rubrum protease targets of $\mathrm{r} 251 \mathrm{HbPI}$ were analyzed by co-immunoprecipitation. $\mathrm{r} 251 \mathrm{HbPI}$ interacted with approximate 27 and $61 \mathrm{kDa}$ T. rubrum proteins, suggesting a role in the inhibition of T. rubrum growth. These results suggest that $251 \mathrm{HbPI}$ could be a candidate for the development of a novel drug to treat $T$. rubrum infection.
\end{abstract}

Keywords: cDNA; dermatophyte; gene expression; potato inhibitor I family; rubber tree.

Abbreviations: 251HbPI_RRIT251 Hevea brasiliensis protease inhibitor; RT-PCR_Reverse transcription polymerase chain reaction; RACE_Rapid amplification of cDNA ends; PI-I_Potato inhibitor I; r251HbPI_Recombinant 251HbPI; PIs_Protease inhibitors; Hb-PI_Hevea brasiliensis RRIM600 latex protease inhibitor; PI1_Hevea brasiliensis protease inhibitor protein 1; CI1A_Subtilisin-chymotrypsin inhibitor-1A; CI-2A_Subtilisin-chymotrypsin inhibitor-2A; CI-1B_Subtilisin-chymotrypsin inhibitor1B; WSCI_Subtilisin-chymotrypsin inhibitor WSCI; SDS-PAGE_Sodium dodecyl sulfate-polyacrylamide gel electrophoresis; MIC_Minimum inhibitory concentration; MFC_Minimum fungicidal concentration.

\section{Introduction}

Protease inhibitors (PIs) are produced by organisms for the regulation of proteolytic activity of their targets. PIs are classified according to the types of protease they inhibit. Serine protease inhibitors are widely produced in microorganisms, animals, and plants. There are inhibitors for almost all the proteolytic enzymes. Based on the protein structure, location of disulfide bridges, and position of the active site, serine protease inhibitors are grouped into eight families: Kunitz, Bowman-Birk, Cucurbitaceae, potato I, potato II, superfamily of inhibitors of cereals, mustard trypsin inhibitor, and Serpin (Koiwa et al., 1997). The potato inhibitor I (PI-I) family of serine protease inhibitors has two distinct biochemical features: a wide range of inhibitory activity against chymotrypsin, trypsin, bacterial subtilisin, Streptomyces griseus endopeptidase, and yeast proteinase B and a lack of the intramolecular disulfide bonds required for stabilization (Beuning et al., 1994). Inhibitors in the PI-I family are generally monomeric and have a molecular weight of approximately $8 \mathrm{kDa}$. The PI-I family is widespread in plants and has been found in many species such as potato tubers (Ryan and Balls, 1962), squash phloem exudates (Murray and Christeller, 1995), barley (Peterson et al., 1991), and wheat (Poerio et al., 2003). The PI-I family has also been found in Hevea brasiliensis RRIM600 latex (Sritanyarat et al., 2006). Trichophyton rubrum most commonly causes difficult-to-control dermatophyte infection in humans. $T$. rubrum can invade keratinous tissues such as skin, hair, and nails during infection by secreting several kinds of proteases. This is considered an important virulence factor (Chen et al., 2010). Some T. rubrum serine proteases of the subtilisin family, such as serine protease encoded by the T. rubrum SUB4 gene, exhibit high keratin-degradation activities (Chen et al., 2010). Recent treatment for T. rubrum infection has primarily been oral (azoles or allylamines, particularly itraconazole) and/or topical (terbinafine) formulations (Gupta and Cooper, 2008). However, the use of medication may be limited by medication interaction, adverse effects, and cost (Gupta and Cooper, 2008). Accordingly, the development of novel approaches to treat $T$. rubrum is necessary.

Since $T$. rubrum secretes protease during infection, this study is interested in PIs from plants that inhibit this protease. The study describes the isolation, cloning, and functional characterization of a serine protease inhibitor of the PI-I family gene from $H$. brasiliensis leaves, a RRIT251 cultivar 
designated RRIT251 H. brasiliensis protease inhibitor (251 Hbpi). H. brasiliensis was selected for this study because it is widely grown in Thailand. Further, a previous study found that protease inhibitor is produced in latex from $H$. brasiliensis (Sritanyarat et al., 2006). However, no protease inhibitors from H.brasiliensis leaves have been identified. To identify the specific proteases targeting $251 \mathrm{HbPI}$, the present work describes the inhibitory activity against major serine proteases, namely, chymotrypsin, subtilisin A, and trypsin. Moreover, this study describes the inhibitory activity of $251 \mathrm{HbPI}$ against $T$. rubrum using a broth-dilution technique. Co-immunoprecipitation was also performed to identify the specific $T$. rubrum proteases targeting $251 \mathrm{HbPI}$.

\section{Results}

\section{Full-length 251Hbpi cDNA isolation}

Figure 1A shows alignments using the CLUSTAL-X program for $\mathrm{H}$. brasiliensis RRIM600 latex protease inhibitor (Hb-PI) (GenBank accession no. EU295479) and H. brasiliensis protease inhibitor protein 1 (PI1) (GenBank accession no. AY221985). Two relatively conserved stretches were designed for the forward primer and the degenerate reverse primer of RT-PCR (Fig. 1A). A partial 251Hbpi sequence was obtained from sequencing of a cDNA fragment amplified by RT-PCR (Fig. 1B) and used to design 3'-RACE and 5'RACE specific primer. The full-length $251 \mathrm{Hbpi}$ sequence was obtained from two RACE-PCR reactions. The fulllength $251 \mathrm{Hbpi}$ sequence was deposited at the NCBI GenBank under accession number KJ471470.

\section{Characterization of the full-length 251 Hbpi gene encoding a homolog of the PI-I family}

The open reading frame of the 251Hbpi cDNA sequence is $213 \mathrm{bp}$ and encodes 70 amino acids containing one cysteine residue. The signature cDNA sequence of $251 \mathrm{Hbpi}$ is a member of the PI-I family of serine protease inhibitors (InterPro IPR000864) analyzed by the InterPro database. SignalP 4.1 analysis identified a lack of a signal peptide of the putative protein. The $251 \mathrm{HbPI}$ amino acid sequence analyzed by the protein-protein BLAST (blastp) program had the highest sequence identity $(84 \%)$ with the serine protease inhibitor of $H$. brasiliensis (GenBank accession no. CCW27997). Multiple sequence alignments of homologous PI-I family proteins from various plant species, including $H$. brasiliensis $(251 \mathrm{HbPI}$; in this study, Hb-PI and PI1), Hordeum vulgare (subtilisin-chymotrypsin inhibitor-1A; CI$1 \mathrm{~A}$ and subtilisin-chymotrypsin inhibitor-2A; CI-2A), Zea mays (subtilisin-chymotrypsin inhibitor-1B, CI-1B), and Triticum aestivum (Subtilisin-chymotrypsin inhibitor WSCI), revealed one motif WPELVG of $251 \mathrm{HbPI}$ conserved across the PI-I family (Fig. 2). The putative active site of $251 \mathrm{HbPI}$ amino acid residues was predicted as $\mathrm{Met}^{46}-\mathrm{Glu}^{47}$ (Fig. 2). The amino acid residues at the active site of $251 \mathrm{HbPI}$ were predicted based on the location of these residues in other known members of the PI-I family (Peterson et al., 1991; Poerio et al., 2003; Sritanyarat et al., 2006; Wang et al., 2003).

\section{Expression and purification of recombinant 251HbPI $($ r251HbPI}

PCR-amplified DNA fragments of $251 \mathrm{Hbpi}$ were cloned into the pFLAG-ATS protein expression vector and induced in Escherichia coli strain BL21 in order to express protein.
Recombinant protein was fused with the FLAG epitope (Nterminal fusion) for purification. Western blot analysis showed expression of r251HbPI. r251HbPI was purified by immunoaffinity using a gravity column packed with antiFLAG M2 affinity gel. The molecular weight of r251HbPI was identified as approximately $11 \mathrm{kDa}$ by performing sodium dodecyl sulfate-polyacrylamide gel electrophoresis (SDS-PAGE) stained with Coomassie Brilliant Blue (Fig. 3). Chymotrypsin, subtilisin $A$ and trypsin inhibition by
r251HbPI

Three major serine proteases: chymotrypsin, subtilisin A, and trypsin were used for the r251HbPI inhibition assays by Colorimetric Quanti-cleave Protease Assay Kit. Independent triplicate performance with similar results showed that r251HbPI inhibited the activity of chymotrypsin and subtilisin A but not trypsin. Inhibition values calculated from tree-independent replications for chymotrypsin and subtilisin A were approximately $24.12 \%$ and $12.23 \%$, respectively (Fig. 4). These results indicate that $r 251 \mathrm{HbPI}$ encodes a functional protease inhibitor that targets chymotrypsin and subtilisin. In addition, r251HbPI has higher chymotrypsin-inhibitory activity than subtilisin A-inhibitory activity.

\section{Anti T. rubrum activity of r251HbPI}

Broth microdilution assay was used to determine the activity of r251HbPI against $T$. rubrum. One-hundred $\mu 1$ of a twofold serially diluted $\mathrm{r} 251 \mathrm{HbPI}$ concentration was inoculated with $100 \mu \mathrm{l}$ of diluted T.rubrum inoculum suspension. Interestingly, the results of the experiment show that r251HbPI inhibited $T$. rubrum growth. Table 1 shows antifungal activity against $T$. rubrum of $\mathrm{r} 251 \mathrm{HbPI}$ at different concentrations ranging from 0.0875 to $44.8 \mathrm{mg} / \mathrm{ml}$. The anti T. rubrum activity of $\mathrm{r} 251 \mathrm{HbPI}$ was effective with minimum inhibitory concentration (MIC) of $0.7 \mathrm{mg} / \mathrm{ml}$ and minimum fungicidal concentration (MFC) of $1.4 \mathrm{mg} / \mathrm{ml}$. MIC and MFC were determined from independent triplicate experiments.

This result demonstrates that $\mathrm{r} 251 \mathrm{HbPI}$ inhibits $T$. rubrum growth, suggesting that $\mathrm{r} 251 \mathrm{HbPI}$ inhibits $T$. rubrum serine protease, which is an important virulence factor secreted during host infection of T. rubrum (Chen et al., 2010).

\section{Interaction between r251HbPI and T. rubrum proteins}

Purified r251HbPI protein was tested for coimmunoprecipitation with secreted T. rubrum proteins. AntiFLAG M2 resin was used for analysis. The result shows that r251 HbPI co-precipitated approximate $27 \mathrm{kDa}$ and $61 \mathrm{kDa}$ of secreted T. rubrum proteins (Fig. 5). This result indicates that both approximate $27 \mathrm{kDa}$ and $61 \mathrm{kDa} T$. rubrum proteins were targets for r251HbPI to inhibit $T$. rubrum growth. These proteins are suggested as $T$. rubrum serine protease.

\section{Discussion}

A large number of organisms, including plants, animals, and microorganisms, have PIs (Valueva and Mosolov, 2004). Generally, plant PIs are small proteins induced in response to injury or attack by pathogens (Ryan, 1990). Moreover, it is produced in storage tissue such as tubers and seeds (Leo et al., 2002). Previously, many H.brasiliensis PIs were found such as $H$. brasiliensis PIs from RRIM600 latex, including HPI-1, HPI-2a, and HPI-2b, which are serine protease inhibitors of the PI-I family (Sritanyarat et al., 2006). They 


\section{(A)}

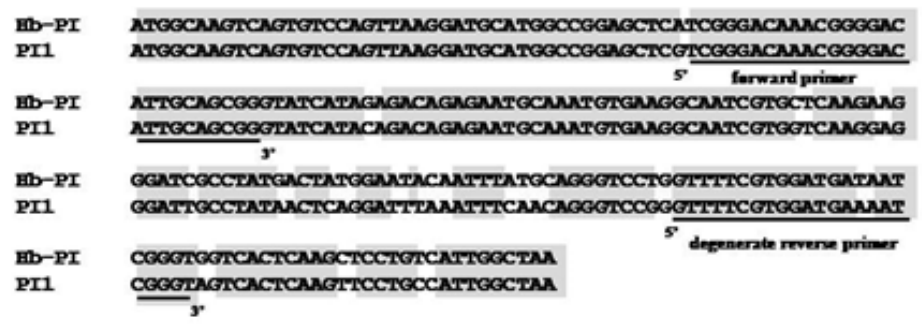

(B)

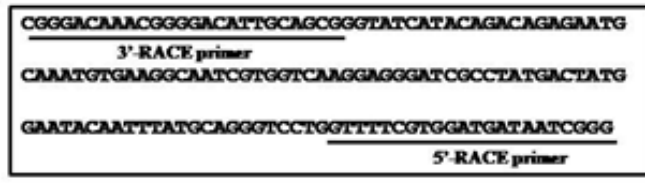

Fig 1. Primers for 251Hbpi isolation. (A) Alignments of $H$. brasiliensis protease inhibitor from Hb-PI and PI1. The conserved sequences are highlighted with a gray background, and DNA primer sequences for RT-PCR are underlined. (B) Partial 251Hbpi sequence from sequencing of cDNA fragment amplified by RT-PCR. DNA primer sequences for RACE-PCR are underlined.

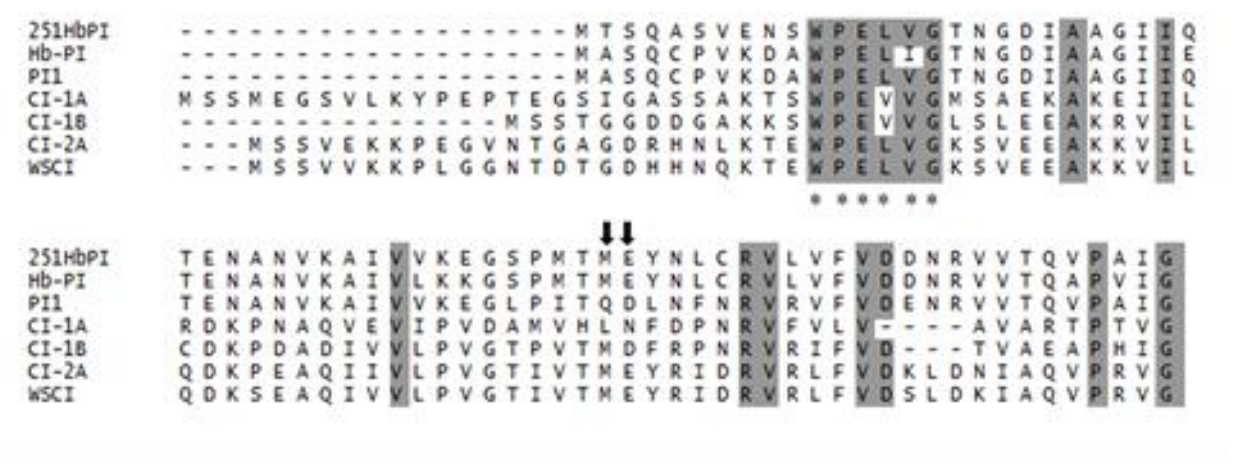

Fig 2. Alignments of the putative $251 \mathrm{HbPI}$ amino acid sequence with members of the PI-I family from various plant species. The amino acid sequence of $251 \mathrm{HbPI}$ was aligned with Hb-PI (H. brasiliensis RRIM600 latex protease inhibitor), PI1 (H. brasiliensis protease inhibitor protein 1), CI-1A (Subtilisin-chymotrypsin inhibitor-1A of $H$. vulgare), CI-1B (subtilisin-chymotrypsin inhibitor1B of Z. mays), CI-2A (Subtilisin-chymotrypsin inhibitor-2A of H. vulgare), and WSCI (Subtilisin-chymotrypsin inhibitor WSCI of T. aestivum). Identical amino acids are highlighted with a gray background. The asterisks indicate amino acid residues of $251 \mathrm{HbPI}$ that were conserved across the PI-I family. The arrows indicate the putative active site of $251 \mathrm{HbPI}$.

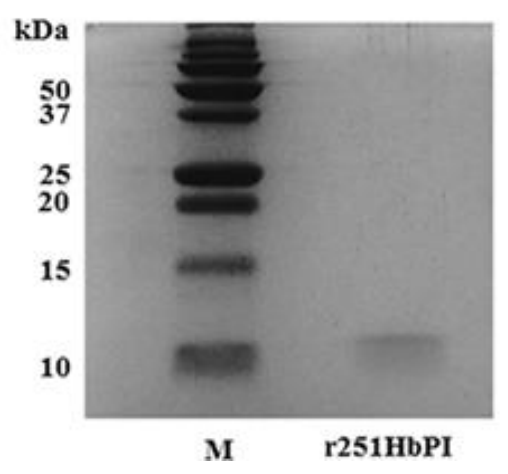

Fig 3. SDS-PAGE separation of purified $251 \mathrm{HbPI}$ protein from the anti-FLAG M2 affinity column stained with Coomassie Brilliant Blue. Lane M indicates the protein standard. Lane r251HbPI represents purified r251HbPI protein from the anti-FLAG M2 affinity column. 


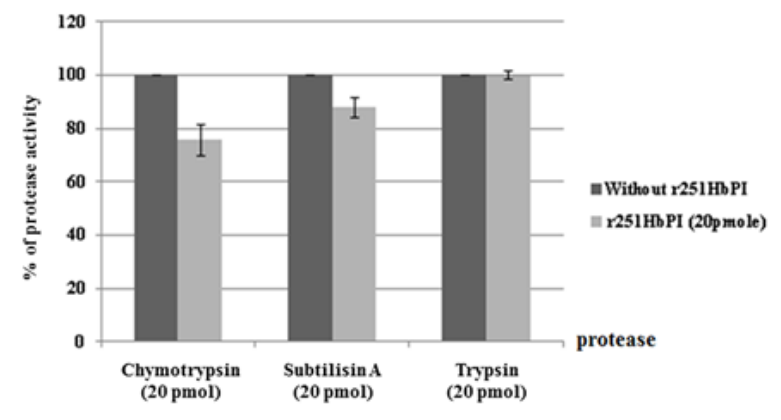

Fig 4. Inhibition of the activities of chymotrypsin, subtilisin A, and Trypsin by r251HbPI. Standard error of deviation was calculated from experiments performed in independent triplicate.

Table 1. Antifungal activity of different concentrations of r251HbPI against T. rubrum.

\begin{tabular}{ccc}
\hline $\begin{array}{c}\text { r251HbPI } \\
\text { Concentration }(\mathbf{m g} / \mathbf{m l})\end{array}$ & $\begin{array}{c}\text { MIC } \\
\text { determination }\end{array}$ & $\begin{array}{c}\text { MFC } \\
\text { determination }\end{array}$ \\
\hline & T. rubrum growth & T. rubrum growth \\
\hline 0.0875 & + & ND \\
0.175 & + & ND \\
0.350 & + & ND \\
0.700 & - & + \\
1.400 & - & - \\
2.800 & - & - \\
5.600 & - & - \\
11.200 & - & - \\
22.400 & - & - \\
44.800 & - & - \\
\hline
\end{tabular}

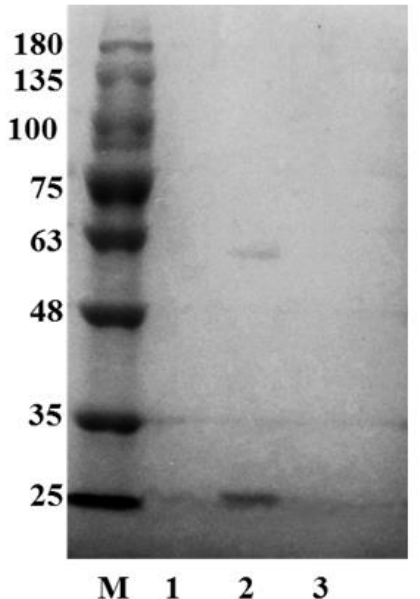

Fig 5. Co-immunoprecipitation of r251HbPI with secreted T. rubrum proteins using anti-FLAG M2 resin. SDS-PAGE gels were stained with Coomassie Brilliant Blue. Lane $\mathrm{M}$ represents the protein standard marker. Lane 1 represents the secreted T. rubrum proteins alone. Lane 2 represents the mixture of secreted T. rubrum proteins incubated with r251HbPI. Lane 3 represents the purified r251HbPI 
hare the same 69 amino acids sequence with the active site at $\mathrm{Gln}^{45}-\mathrm{Asp}^{46}$. In addition, H. brasiliensis RRIM600 latex produces $\mathrm{HbCPI}$, a cysteine protease inhibitor that is $306 \mathrm{bp}$, encodes 101 amino acids with motifs of the phytocystatin superfamily, and inhibits the protease activity of papain (Bangrak and Chotikeat, 2011). However, no protease inhibitors acting against chymotrypsin and subtilisin have been identified from H.brasiliensis RRIT251 leaves. PIs of the PI-I family that $251 \mathrm{HbPI}$ protein encodes almost found in the storage tissue of plants. However, these PIs can be found in leaves, for example, sweet potato leaf trypsin inhibitor (Wang et al., 2003). 251HbPI contains one cysteine. In contrast with other families of protease inhibitors, PI-I family members lack disulfide bonds. The s-s bond is not involved in the inhibitory activity of PIs of the PI-I family (Poerio et al., 2003). InterPro database analysis indicates the $251 \mathrm{HbPI}$ amino acid sequence lacks signal peptide, unlike other $H$. brasiliensis PIs. However, secretory proteins that lack signal peptide can be secreted without $\mathrm{N}$-terminal signal peptides (Bendtsen et al., 2005), such as fibroblast growth factor-1, fibroblast growth factor-2, interleukins-1 beta, and galectins, and can be exported by a distinct non-classical secretion pathway (Huang, 2012). Many bacteria proteins are released via the secretion and twin-arginine translocation pathways, which are non-classical secretion pathways (Bendtsen et al., 2005). The active site of $251 \mathrm{HbPI}$ was predicted as $\mathrm{Met}^{46}$ $\mathrm{Glu}^{47}$ (Fig. 2) based on the other known members of PI-I family, namely, Met-Glu (Svendsen et al., 1980), Met-Asp (Richardson, 1977), Leu-Asp (Richardson, 1977), Ala-Asp (Svendsen et al., 1984), and Lys-Asp (Wingate et al., 1989). These agree with $\mathrm{P}_{1}$ and $\mathrm{P}_{1}{ }_{1}$ positions of PI-I family active sites that almost are hydrophobic residues (methionine, alanine, and leucine) and acidic residues, respectively (Poerio et al., 2003). Moreover, the presence of a single active site per polypeptide chain is a normal feature in inhibitors belonging to the PI-I family (Poerio et al., 2003). r251HbPI inhibits chymotrypsin and subtilisin A but not trypsin. This result contrasts with PI-I family proteins from $H$. brasiliensis latex (HPI-1, HPI-2a and HPI-2b), which inhibit subtilisin A, weakly inhibit trypsin, and do not inhibit chymotrypsin (Sritanyarat et al., 2006). From the functional characterization study of $251 \mathrm{HbPI}$, the authors believe that $251 \mathrm{HbPI}$ is a novel protease inhibitor of the PI-I family found in $H$. brasiliensis RRIT251 leaves.

The r251HbPI inhibits T. rubrum growth, which suggests r251HbPI inhibits $T$. rubrum proteases, most likely a serine protease. Secreted proteases from T. rubrum are likely important in invasion, utilization, and subsequent dissemination (Chen et al., 2010). Nearly 20 genes encoded for secreted proteases have been identified from T. rubrum. Seven genes, SUB1-7, are encoded for the putative serine protease of the subtilisin family (Chen et al., 2010; Jousson et al., 2004). r251HbPI co-precipitates with approximate 27 $\mathrm{kDa}$ and $61 \mathrm{kDa}$ T. rubrum proteins (Fig. 5). Therefore, these proteins are predicted as T. rubrum protease. A previous study found that $27 \mathrm{kDa}$ T. rubrum protein is serine protease and is inhibited by serine proteinase inhibitors (Apodaca and McKerrow, 1989). The functions of $27 \mathrm{kDa}$ protease are poor keratinase activity but are involved with metabolism and invasion by interaction with the $5 \%$ of nonkeratinous proteins contained in the stratum corneum (Apodaca and McKerrow, 1989; Sun and Green, 1978). T. rubrum protease with molecular weight of $27 \mathrm{kDa}$ is general protease akin to trypsin or chymotrypsin of serine protease (Apodaca and McKerrow, 1989). Accordingly, this may be one of the reasons that $\mathrm{r} 251 \mathrm{HbPI}$ is effective for anti $T$. rubrum activity.
However, the function of $T$. rubrum protein with molecular weight of $61 \mathrm{kDa}$ has not been studied previously.

\section{Materials and Methods}

\section{Plant material}

Rubber plants (H. brasiliensis, RRIT251 cultivar) were grown in pots at $25^{\circ} \mathrm{C}$ with a 12-h photoperiod. Eight-weekold leaves of rubber plants without infection were used for RNA extraction.

\section{T. rubrum culture and protein extraction}

A clinical isolate of T. rubrum was obtained from Trang Regional Center of Tropical Dermatology, Thailand. T. rubrum was maintained and cultivated on Sabouraud dextrose agar at $28{ }^{\circ} \mathrm{C}$. To obtain secreted proteins from T. rubrum, a volume of $100 \mathrm{ml}$ Sabouraud broth was inoculated with 14day-old T. rubrum mycelium. The culture was incubated for 21 days at $30^{\circ} \mathrm{C}$. The culture supernatant was filtered through $0.45 \mu \mathrm{m}$ filter membrane and precipitated with trichloroacetic acid on ice for $1 \mathrm{~h}$. The protein pellet was collected by centrifugation at $14,000 \mathrm{rpm}$ for $15 \mathrm{~min}$ at $4^{\circ} \mathrm{C}$ and was washed three times with cold glacial acetone.

\section{Construction of full-length $251 \mathrm{Hbpi}$ cDNA}

Leaves $(100 \mathrm{mg})$ of the eight-week-old rubber plants were ground in liquid nitrogen using a mortar and pestle. RNA was extracted from the ground leaves using the RNeasy plant mini kit (Qiagen). RNA concentration was measured at $260 \mathrm{~nm}$ by spectrophotometry. Total RNA was treated with DNA-Free (Ambion, Austin, TX) before RT-PCR. Three $\mu \mathrm{g}$ of total RNA was used for first-strand cDNAs synthesis using the SuperScript III RT-PCR System (Invitrogen). The CLUSTAL-X program was used for alignment to design DNA primers of 251 Hbpi. The conserved regions from alignments of Hb-PI (GenBank accession no. EU295479) and PI (GenBank accession no. AY221985) were used to create primers for 251 Hbpi. Both Hb-PI and PI1 sequences were obtained from the NCBI database (www.ncbi.nlm.nih.gov). Forward primer (5'-TCGGGACAAACGGGGACATTGCAGCG-3') and degenerate reverse primer (5'CCCGATTWTCATCCACGAAAACC-3') were used for RTPCR. A full-length $251 \mathrm{Hbpi}$ cDNA sequence was obtained from RACE-PCR using the Smart RACE cDNA amplification kit following the manufacturer's instructions (Clontech). Forward primer (5'-CGGGACAAACGGGGACATTGCAGCG-3') was used for 3'-RACE, and reverse primer (5'-CCCGATTATCATCCACGAAAACC-3') was used for 5'-RACE. The obtained partial 251 Hbpi sequence from RT-PCR was used to design RACE-PCR reaction primers.

\section{Cloning and sequencing}

PCR product obtained from RACE-PCR was transformed to E.coli TOP10 cells by mixing $4 \mu \mathrm{l}$ of PCR product, $1 \mu \mathrm{l}$ of TOPO PCR 2.1 Vector (Invitrogen), and $1 \mu 1$ of salt solution $\left(1.2 \mathrm{M} \mathrm{NaCl}\right.$ and $\left.0.06 \mathrm{M} \mathrm{MgCl}_{2}\right)$. The ligation reaction was incubated at room temperature for $15 \mathrm{~min}$. Five $\mu \mathrm{l}$ of the ligation reaction was added to E. coli TOP10 cells and placed in ice for $30 \mathrm{~min}$ then heated at $42^{\circ} \mathrm{C}$ for $45 \mathrm{sec}$. The reaction was put in ice for $1 \mathrm{~min}$ and then removed. Subsequently, 300 $\mu \mathrm{l}$ of Luria Bertani media broth was added to the reaction. The culture was grown at $37^{\circ} \mathrm{C}, 250 \mathrm{rpm}$ for $1 \mathrm{~h}$ and spread 
on Luria Bertani media agar containing kanamycin (25 $\mu \mathrm{g} / \mathrm{ml})$. Twenty colonies were picked and struck on new Bertani media agar containing kanamycin $(25 \mu \mathrm{g} / \mathrm{ml})$ and incubated at $37^{\circ} \mathrm{C}$ overnight. For sequencing, plasmids were extracted from the cloned cells using the QIAprep Spin Miniprep Kit (Qiagen).

\section{Sequence analysis}

The InterPro (http://www.ebi.ac.uk/interpro/) and SignalP 4.1 databases were used for analysis of the PI family and signal peptide, respectively. Comparison of the amino acid sequences of the PI-I family from 251HbPI, Hb-PI (GenBank accession no. EU295479), PI1 (GenBank accession no. AY221985), $H$. vulgare (CI-1A) (GenBank accession no. P16062), Z. mays (CI-1B) (GenBank accession no. ACG26339), H. vulgare (CI-2A) (GenBank accession no. P01053) (Peterson et al., 1991), and T. aestivum (WSCI) (GenBank accession no. P82977) (Poerio et al., 2003) was conducted using the CLUSTAL-X program. All sequences were obtained from the NCBI database (www.ncbi.nlm.nih.gov).

\section{Construction of expression cassette}

The pFLAG-ATS vector (Sigma) was used to construct recombinant plasmid. A PCR-amplified DNA fragment of $251 \mathrm{Hbpi}$ was cloned into the EcoRI and KpnI sites of pFLAG-ATS. The pFLAG-251HbPI plasmid was transformed into E. coli strain BL21 using an electroporator at 2,500 volts. The recombinant clone was sequenced again to affirm that there was no sequence error.

\section{Expression and purification}

r251HbPI protein was expressed in E. coli strain BL21 and purified using anti-FLAG M2 affinity gel (Sigma). Protein was eluted with $0.1 \mathrm{M}$ glycine $(\mathrm{pH} 3.5$ ) from the column. Protein concentration was measured at $280 \mathrm{~nm}$ by spectrophotometry and calculated using an extinction coefficient of $6990 \mathrm{M}^{-1} \mathrm{~cm}^{-1}$.

\section{Polyacrylamide gel electrophoresis and western blot analysis}

Molecular weight of r251HbPI was evaluated by SDS-PAGE using $15 \%(\mathrm{w} / \mathrm{v})$ polyacrylamide. The sample was mixed with $2 x$ loading buffer in a 1:1 ratio and boiled for $5 \mathrm{~min}$ before loading. The $1 \mathrm{x}$ SDS-PAGE running buffer was used for electrophoresis, which was performed with 90 volts for the stacking gel and 120 volts for the separating gel. The apparent molecular weight of r251HbPI was determined using a Precision Plus Protein Standard (10-250 kDa; Bio$\mathrm{Rad})$. After electrophoresis, the separated protein was stained with Coomassie Brilliant Blue (Sambrook et al., 1989) or transferred to nitrocellulose membranes with a trans-blot semi-dry apparatus (Bio-Rad) following the manufacturer's instructions. Expression of r251HbPI was detected with ANTI-FLAG M2 peroxidase (Sigma) and Super Signal West Pico chemiluminescent substrate (Pierce).

Quantitative analysis of chymotrypsin, subtilisin A, and trypsin inhibitory activity of r251HbPI

For protease inhibition analysis, the Colorimetric Quanticleave Protease Assay Kit (Pierce) was used according to the manufacturer's instructions. Before analysis, 20 pmol of r251HbPI was incubated with 20 pmol of chymotrypsin, subtilisin A, or trypsin at a volume of $50 \mu \mathrm{l}$ for $30 \mathrm{~min}$ at room temperature. The substrate for this study was $2 \mathrm{mg} / \mathrm{ml}$ succinylated casein. The reactions were measured for protease activity at $450 \mathrm{~nm}$ by spectrophotometry. This experiment was performed in independent triplicate for each protease.

\section{Inoculum preparation}

The 14-day-old culture grown in Petri dishes containing Sabouraud dextrose agar of T.rubrum was covered with $0.85 \%$ sodium chloride and the surface was scraped with a tip. To obtain microconidia of T.rubrum, the solution of conidia and hyphae was filtrated through Whatman Filter Model 40 (Santos and Hamdan, 2005). The microconidia in the filtrate were counted with a hematocytometer and diluted in Sabouraud dextrose broth to obtain a final concentration of approximately $10^{6} \mathrm{CFU} / \mathrm{ml}$ (Sajomsang et al., 2012).

\section{MIC and MFC determination}

To evaluate the anti T.rubrum activity of r251HbPI, MIC was determined using the broth-dilution technique and performed according to the CLSI reference method (Fothergill, 2002). A two-fold serial dilution of r251HbPI was made in concentrations ranging from 0.0875 to 44.8 $\mathrm{mg} / \mathrm{ml}$ using Sabouraud dextrose broth. Each well of the 96well plates contained $100 \mu \mathrm{l}$ of the two-fold serially diluted r251HbPI concentration was inoculated with $100 \mu \mathrm{l}$ of diluted T.rubrum inoculum suspension. The positive control was $100 \mu \mathrm{l}$ of Sabouraud dextrose broth plus $100 \mu \mathrm{l}$ of diluted T.rubrum inoculum suspension. The two negative controls were Sabouraud dextrose broth and Sabouraud dextrose broth plus r251HbPI. The 96-well plates were incubated at $28^{\circ} \mathrm{C}$ for 7 days. MIC value, defined as the lowest concentration showing no visualized growth in the test well, was compared with the positive control. MFC value was determined by plating $10 \mu \mathrm{l}$ aliquots in 96-well plates resulting from MIC determinations onto Sabouraud dextrose agar plates. The plates were incubated at $28^{\circ} \mathrm{C}$ for 7 days and then observed for T.rubrum growth. MFC was defined as the lowest concentration of the subculture showing no development of T.rubrum on Sabouraud dextrose agar (Rodrigues et al., 2012). Both MIC and MFC determinations were performed in independent triplicate.

\section{Co-immunoprecipitation}

Purified protein of $\mathrm{r} 251 \mathrm{HbPI}(1.6 \mathrm{nmol})$ was incubated with $200 \mu \mathrm{l}(0.12 \mathrm{mg})$ of secreted $T$. rubrum proteins for $30 \mathrm{~min}$ at $25^{\circ} \mathrm{C}$. Forty $\mu 1$ of anti-FLAG M2 resin (Sigma) was added to the mixture and incubated at $4^{\circ} \mathrm{C}$ overnight with gentle shaking. The unbound proteins in the supernatant were discarded by centrifugation at $8,000 \mathrm{rpm}$ for $30 \mathrm{sec}$. The resin was washed four times with $1 \mathrm{ml}$ of $1 \mathrm{x}$ Tris-buffered saline. To elute bound protein complexes, $60 \mu \mathrm{l}$ of $0.1 \mathrm{M}$ glycine (pH 3.5) was added to the resin and incubated for $5 \mathrm{~min}$ with gentle shaking, followed by centrifugation at $8,000 \mathrm{rpm}$ for $30 \mathrm{sec}$. The bound proteins in the supernatant were mixed with $6 \mu 1$ of $0.5 \mathrm{M}$ Tris- $\mathrm{HCl} \mathrm{pH}$ 8.0. The protein complexes were analyzed using an $8 \%$ gel for SDS-PAGE and stained with Coomassie Brilliant Blue.

\section{Conclusion}

In conclusion, $251 \mathrm{HbPI}$ is in the PI-I family of serine protease inhibitors that target chymotrypsin and subtilisin A. r251HbPI has antifungal activity against $T$. rubrum. The 
targets for $\mathrm{r} 251 \mathrm{HbPI}$ to inhibit $T$. rubrum growth are approximate $27 \mathrm{kDa}$ and $61 \mathrm{kDa} T$. rubrum proteins.

\section{Acknowledgements}

This research was supported by the Walailak University Fund. The authors wish to thank Trang Regional Center of Tropical Dermatology, Thailand for providing the T. rubrum samples.

\section{References}

Apodaca G, McKerrow JH (1989) Purification and characterization of a 27,000-Mr extracellular proteinase from Trichophyton rubrum. Infect Immun. 57:3072-3080.

Bangrak P, Chotikeat W (2011) Molecular cloning and biochemical characterization of a novel cystatin from Hevea rubber latex. Plant Physiol Bioch. 49:244-250.

Bendtsen JD, Kiemer L, Fausboll A, Brunak S (2005) Nonclassical protein secretion in bacteria. BMC Microbiol. 5:58.

Beuning LL, Spriggs TW, Christeller JT (1994) Evolution of the proteinase inhibitor I family and apparent lack of hypervariability in the proteinase contact loop. J Mol Evol. 39:644-654.

Chen J, Yi J, Liu L, Yin S, Chen R, Li M, Ye C, Zhang YQ, Lai W (2010) Substrate adaptation of Trichophyton rubrum secreted endoproteases. Microb Pathogenesis. 48:57-61.

Fothergill AW (2002) CLSI-clinical laboratory standards institute, Reference method for broth dilution antifungal susceptibility testing of filamentous fungi, approved standard document M38-A, Pennsylvania

Gupta AK, Cooper EA (2008) Update in antifungal therapy of dermatophytosis. Mycopathologia. 166:353-367.

Huang W (2012) Ranking Gene Ontology terms for predicting non-classical secretory proteins in eukaryotes and prokaryotes. J Theor Biol. 312:105-113.

Jousson O, Léchenne B, Bontems O, Mignon B, Reichard U, Barblan J, Quadroni M, Monod M (2004) Secreted subtilisin gene family in Trichophyton rubrum. Gene. 339:79-88.

Koiwa H, Bressan RA, Hasegawa PM (1997) Regulation of protease inhibitors and Plant defense. Trends Plant Sci. 2:379-384.

Leo F, Volpicella M, Licciulli F, Liuni S, Gallerani R, Ceci L (2002) PLANT-PIs: a database for plant protease inhibitors and their genes. Nucleic Acids Res. 30:347- 348.

Murray C, Christeller JT (1995) Purification of trypsin inhibitor (PFTI) from pumpkin fruit phloem exudates and isolation of putative trypsin and chymotrypsin inhibitor cDNA clones. Biol Chem H-S. 376:281-287.

Peterson DM, Forde J, Williamson MS, Rohde W, Kreis M (1991) Nucleotide Sequence of a Chymotrypsin Inhibitor-2 Gene of Barley (Hordeum vulgare L.). Plant Physiol. 96:1389-1390.
Poerio E, Gennaro S, Maro A, Farisei F, Ferranti P, Parente A (2003) Primary structure and reactive site of a novel wheat proteinase inhibitor of subtilisin and chymotrypsin. Biol Chem. 384:295-304.

Richardson M (1977) The proteinase inhibitors of plants and microorganisms. Phytochemistry. 16:159-169.

Rodrigues ER, Nogueira NG, Zocolo GJ, Leite FS, Januario AH, Fusco Almeida AM, Fachin AL, de Marchi MR, dos Santos AG, Pietro RC (2012) Pothomorphe umbellata: antifungal activity against strains of Trichophyton rubrum. J Mycol Med. 22:265-269.

Ryan CA (1990) Proteinase inhibitors in plants: genes for improving defenses against insects and pathogens. Annu Rev Phytopathol. 28:425-449.

Ryan CA, Balls AK (1962) An inhibitor oh chymotrypsin from Solanum tuberosm and its behavior toward trypsin. Proc Natl Acad Sci U S A. 48:1839-1844.

Sajomsang W, Gonil P, Saesoo S, Ovatlarnporn C (2012) Antifungal property of quaternized chitosan and its derivatives. Int J Biol Macromol. 50:263-269.

Sambrook J, Fritsch EF, Maniatis T (1989) Molecular Cloning: A Laboratory Manual, 2nd edn. Cold Spring Harbor Laboratory, Cold Spring Harbor, New York

Santos DA, Hamdan JS (2005) Evaluation of Broth Microdilution Antifungal Susceptibility Testing Conditions for Trichophyton rubrum. J Clin Microbiol. 43:1917-1920.

Sritanyarat W, Pearce G, Siems WF, Ryan CA, Wititsuwannakul R, Wititsuwannakul D (2006) Isolation and characterization of isoinhibitors of the potato protease inhibitor I family from the latex of the rubber trees, Hevea brasiliensis. Phytochemistry. 67:1644-1650.

Sun TT, Green H (1978) Keratin filaments of cultured human epidermal cells. Formation of intermolecular disulfide bonds during terminal differentiation. J Biol Chem. 253:2053-2060.

Svendsen I, Hejgaard J, Chavan JK (1984) Subtilisin inhibitor from seeds of broad bean (Viciafaba); purification, amino acid sequence and specificity of inhibition. Carlsberg Res Commun. 49:493-502.

Svendsen I, Jonassen I, Hejgaard J (1980) Amino acid sequence homology between a serine protease inhibitor from barley and potato Inhibitor I. Carlsberg Res Commun. 45:389-395.

Valueva TA, Mosolov VV (2004) Role of inhibitors of proteolytic enzymes in plant defense against hytophathogenic microorganisms. Biochemistry-US. 69:1305-1309.

Wang HY, Huang YC, Chen SF, Yeh KW (2003) Molecular cloning, characterization and gene expression of a water deficiency and chilling induced proteinase inhibitor I gene family from sweet potato (Ipomoea batatas Lam.) leaves. Plant Sci. 165:191-203.

Wingate VPM, Broadway RM, Ryan CA (1989) Isolation and characterization of a novel, developmentally regulated proteinase inhibitor I protein and cDNA from the fruit of a wild species of tomato. J Biol Chem. 264:17734-17738. 